\section{"THE ELECTROLYTIC TRANSMISSION OF SULPHUR."}

To the Editors of THE LANCET.

SIRS, - I read with interest Dr. F. W. Smith's contribution on "The Electrolytic Transmission of Sulphur" to THE LANCET of August 10th, p. 371. But I do not know what "the positive end of an anode" is ; nor do I know the meaning of the "negative anode." I suppose the former to mea "anode" merely, and the latter "kathode." Is the experiment detailed not connected with electrical osmosis? Perhaps some one of your correspondents versed in electrical science will enlighten those of your readers who are in doubt.

August 12th, 1901.

I am, Sirs, yours faithfully,

$\mathrm{X}$.

\section{"THE TIMES ARE TROUBLOUS."}

\section{To the Editors of THE LANCET.}

Strs,-Most of us will agree with your correspondent, "G. P." in his excellent diagnosis as to the causes of that wasting complaint which he calls "troublous times." He indicates its chief causes and hints at the one effectual remedy, yet he shrinks from and even deprecates its use because "he has been taught to believe that it is on the whole derogatory to us as a profession" to dispense the medicines we order. Now is that teaching true? Unfortunately, I cannot, like "G. P.," "boast my youth," and I believe in the view of the teachers of my unregenerated era, which was diametrically the opposite, and in practice have conformed thereto. I am a hardened sinner and confess to feeling no shame. If it has sunk me in the estimation of my patients they have not shown it. It certainly does not prevent them returning to me regularly for advice or from bringing other sick friends with them.

To treat disease it is surely important to see the patient regularly, perhaps frequently. To insure his doing this make him come to you for his drugs, to be continued, modified, or changed as you see fit, and do not put it in his power by giving him a prescription to go the easier and cheaper and sometimes harmful way of sending for the "mixture as before" to the druggist. What a terrible deal of useless drugging is done by weeks' or even months' use of a prescription. We can prevent all this by home dispensing; but, then, is it really derogatory? Is a man less a man? Is his opinion or advice thought to be of less worth? Is the country practitioner held in less esteem by any but the snob because his medicines are dispensed from his own surgery? Is he degraded? It is an important question worthy of careful consideration by the general practitioner of the future and not one to answer hastily. The sowing of prescriptions broadcast produces a great consumption of drugs, but it is often the advice and the supervision, rather than the drug, that are needed by the sick man. We read of an important man who, although suffering from a loathsome disease, felt it derogatory to his position to make use of a simple and agreeable cure by washing in waters inferior to his own. Did anyone think the worse of him because on further consideration he put his dignity in his pocket and washed himself and his pride clean?

August 12th, 1901

$$
\text { I am, Sirs, yours faithfully, }
$$

\section{A PROPOSITION FOR THE REGENERATION OF THE ROYAL ARMY MEDICAL} CORPS.

To the Editors of THE LANCET.

SIRS, - It appears to me that the position of the above department is becoming crucial. The country evidently requires a remodeled army and it must occur even to the mind of the stupidest of our combatants that to keep that army in the field exceptionally good medical officers are necessary. The question therefore arises, How are we to get them? The following I propose as a solution. We cannot make a clean sweep of the Royal Army Medical Corps and begin afresh but we can offer them and men willing to join now the following terms. 12 years' initial service under present conditions; during the last three years of this initial service every possible opportunity for the acquisition of scientific medical knowledge. They should during these three years pass a really high standard examination-e.g., the M.B. and B.C. examination of Cambridge. On passing this examination that they should be qualified for promotion.

Let us have a look at our medico. Now, what do we find ? We find a man with 12 years' army service, with a thorough knowledge of that service and of its discipline, and beyond this an exceptionally high professional standing. Now, I say that such a man if he elects to leave the service will have no difficulty whatever in making a good practice with its attendant income. But the army and the nation sustain a loss. How, then, can they keep him? They must pay him-I do not say respect him, they do that already. Give him then from $£ 800$ to $£ 1000$ a year and rank him as surgeon first grade? What higher title? What shall we do with the men who fail to pass? Let them go on under the old warrant until they $d o$, but always, whatever may be their age and infirmities, as subordinate to the first grade man. If the authorities will do this they will get some of the best young medical men in the country. I submit this as a rough sketch ; of course, many points require elaboration. I inclose my card and remain, Yours faithfully,

August 13th, 1901. TRUE BLUE,

\section{NOTES FROM INDIA.}

(From oUR Special Correspondent.)

\section{A Rising Plague Mortality.-The Hamilton Sub-Committee and the Indian Medical Service.}

THE plague epidemic, which may be said to have been slumbering for some time, is now apparently waking up again. The mortality increases week by week; the returns made up to July 20th show 1455 cases, against 1258 in the week preceding. The development is taking place in the Bombay Presidency and the neighbouring Mysore State. The figures are : Bombay district, 1174, against 1048 ; Bombay city, 105, against 85 ; Mysore State, 129, against 97 . Elsewhere the mortality is very small, Calcutta reporting 11 , against 16 ; and the Bengal districts 7, against 2. Karachi, unfortunately, has had another case and the notification declaring it to be free has had to be cancelled. Bombay city seems to be very unfortunate. After the worst of the outbreak in the spring passed away the high mortality only slowly declined, but the death-rate never returned to normal Now during the past week or two it has risen again and plague has recrudesced unmistakeably in the north of the island. The last returns show the week's total to have been 738 deaths from all causes, giving a rate of 47.08 per 1000 . There were 101 deaths from plague.

There has been a great discussion in the lay press over the report of the "Hamilton Sub-Committee." It seems to have excited considerable opposition from the Indian Medical Service. Absorption into the Royal Army Medical Corps would leave India with no distinctive medical service and service in India would be looked upon with anything but favour. The only advantage would be the abolition of the dual control at headquarters and with it the friction between the two services. The arguments seem stronger for the whole medical service of the army in India being under the Indian Medical Service. The present discontent in, and unpopularity of, the Indian Medical Service is due to what may be termed cumulative causes. Short-handedness, causing extra work and little leave, is one. The attractions of the service have also diminished. The profits of private practice in India have been steadily diminishing, due to the turning out of a larger number of improved native practitioners who charge comparatively small fees. Government has curtailed the field of practice and has not raised the official emoluments. Government has regulated the fees which members of the Indian Medical Service are allowed to charge for medical attendance on native notables. For this there is not the slightest justification. Barristers fix their fees without let or hindrance and have taken a vast deal more out of the rich native's pocket than ever the Indian Medical Service did. Again, the privilege of private practice has been taken from four of the professors of the Lahore Medical College and the official Onder now limits them to consulting work. If this innovation is to be extended the emoluments of the chairs will have to be considerably increased. At one time the Indian Medical Service was nearly level with the Civil Service, now for the abovementioned reasons it has been left a long: way behind. To 